\title{
BMJ Open Learning outcomes for communication skills across the health professions: a systematic literature review and qualitative synthesis
}

\author{
Charlotte Denniston, ${ }^{1}$ Elizabeth Molloy, ${ }^{1,2}$ Debra Nestel, ${ }^{1,3}$ Robyn Woodward-Kron, ${ }^{2}$ \\ Jennifer L Keating ${ }^{4}$
}

To cite: Denniston C, Molloy E, Nestel D, et al. Learning outcomes for communication skills across the health professions: a systematic literature review and qualitative synthesis. BMJ Open 2017;7:e014570. doi:10.1136/bmjopen-2016014570

- Prepublication history and additional material is available. To view please visit the journal (http://dx.doi.org/ 10.1136/bmjopen-2016014570).

Received 4 October 2016 Revised 21 November 2016 Accepted 11 January 2017

\section{CrossMark}

${ }^{1}$ Faculty of Medicine, Nursing and Health Sciences, Monash University, Melbourne, Victoria, Australia

${ }^{2}$ Department of Medical Education, University of Melbourne, Melbourne, Victoria, Australia ${ }^{3}$ Department of Surgery (Austin), University of Melbourne, Melbourne, Victoria, Australia

${ }^{4}$ Department of Physiotherapy, Monash University, Melbourne, Victoria, Australia

\section{Correspondence to} Charlotte Denniston; charlotte.denniston@monash. edu

\section{ABSTRACT}

Objective: The aim of this study was to identify and analyse communication skills learning outcomes via a systematic review and present results in a synthesised list. Summarised results inform educators and researchers in communication skills teaching and learning across health professions.

Design: Systematic review and qualitative synthesis.

Methods: A systematic search of five databases (MEDLINE, PsycINFO, ERIC, CINAHL plus and Scopus), from first records until August 2016, identified published learning outcomes for communication skills in health professions education. Extracted data were analysed through an iterative process of qualitative synthesis. This process was guided by principles of person centredness and an a priori decision guide.

Results: 168 papers met the eligibility criteria; 1669 individual learning outcomes were extracted and refined using qualitative synthesis. A final refined set of 205 learning outcomes were constructed and are presented in 4 domains that include: (1) knowledge (eg, describe the importance of communication in healthcare), (2) content skills (eg, explore a healthcare seeker's motivation for seeking healthcare),(3) process skills (eg, respond promptly to a communication partner's questions) and (4) perceptual skills (eg, reflect on own ways of expressing emotion).

Conclusions: This study provides a list of 205 communication skills learning outcomes that provide a foundation for further research and educational design in communication education across the health professions. Areas for future investigation include greater patient involvement in communication skills education design and further identification of learning outcomes that target knowledge and perceptual skills. This work may also prompt educators to be cognisant of the quality and scope of the learning outcomes they design and their application as goals for learning.

\section{INTRODUCTION}

It is widely acknowledged that skilled communication is essential for all health professionals. For the purposes of this paper, communication is defined as a two-way process involving

\section{Strengths and limitations of this study}

- As far we are aware, no previous paper has reported a comprehensive systematic literature review and qualitative synthesis of learning outcomes in communication skills across the health professions.

- Learning outcomes were restructured using qualitative synthesis to remove duplication and ambiguity; and to be concise, defined and accessible to educators developing individualised education programmes.

- The final list provides a comprehensive summary of published literature for consideration by patients, educators, learners and other stakeholders.

- The search strategy was limited to the English language and the specific education of communication skills. By restricting the search strategy, we may have excluded papers that contained relevant learning outcomes.

speech, writing or non-verbal means that aim to create shared interpretation for those involved. ${ }^{1}$ As such, effective communication skills are emphasised as a target for health professional education programmes locally ${ }^{2}$ and internationally (including medicine, physiotherapy ${ }^{4}$ and across interprofessional groups $\left.{ }^{5}\right)$. Over the past 20 years, there has been a growth in communication skills research, and the implementation of communication skills programmes in entry-level medical programmes has become commonplace worldwide. ${ }^{6}{ }^{7}$ Despite its recognition as a key competency for practice, communication skills teaching has not been routinely adopted in all health professional programmes, and discourse related to communication skills pedagogy remains less common outside medicine. ${ }^{8}$

The literature on learning and teaching communication skills includes guides and 
consensus statements for doctor-patient communication (such as Calgary Cambridge Referenced Observation Guides, the UK Consensus Statement, the Kalamazoo Consensus Statement and the German Basel Consensus Statement).$^{9-12}$ The content of these documents could be presented as intended learning outcomes (ie, what learners are expected to be able to know and/or do after participation in an education programme). However, many of the individual items in these documents target multiple constructs and do not directly translate into specific learning goals.

\section{Learning outcomes in education design}

For many years, researchers in education have proposed alternate ways of structuring goals in educational design. From the 1960s, the term 'instructional objective' was used to define a statement expressing what learners should be able to do at the end of the learning period. ${ }^{13}$ These instructional objectives were designed to be constructively aligned with methods for teaching and assessment. ${ }^{14}$ Learning objectives have been described as focusing more discretely on observable knowledge, attitudes and skills, whereas the more contemporary term 'outcome' is defined as a broader statement of what is achieved and assessed at the end of a course of study. ${ }^{15} 16$ More recently, competency-based medical education (CBME) argues for education organised around a defined set of competencies towards which learning is targeted to achieve proficiency. ${ }^{17}$ Competencies have been defined as the observable capabilities of a health professional (ie, knowledge, skills, values and attitudes).$^{18}$ Grant $^{19}$ and Prideaux ${ }^{20-22}$ argue that the differentiation of terms is not greatly important, as long as the goals for learning are clear. Regardless of semantics, it is acknowledged that some aspects of healthcare practice are difficult to define in these terms, and the identification of an objective, outcome or a competency may not specify exactly what is to be achieved..$^{20}$ This argument suggests that the 'sum' of healthcare practice is far greater than the 'parts' and that any reduction of complex human behaviour into objectives or competencies may be seen as unhelpful. ${ }^{24}$ This stance resonates with reports within the communication skills literature, which argue that communication also cannot be separated into its parts. ${ }^{25}$

\section{Communication as a skill}

Although learners may develop many aspects of communication through experience prior to university, ${ }^{26} 27$ effective communication in the context of healthcare practice is highly technical and is likely to require training, deliberate targeted practice and feedback to develop skilled performance. ${ }^{28} 29$

One school of thought in the communication literature is that positioning communication as a set of behavioural skills is reductionist and mistaken. ${ }^{25} 30{ }^{31} \mathrm{It}$ has been argued that the 'atomisation' of communication into discrete observable skills may not take into consideration the complexity of a communication interaction, and nor does it consider the authenticity and creativity required in complex practice. ${ }^{25} 31$ These authors also argue that the deployment of a communication skill does not necessarily equate to skilled communication. ${ }^{25}{ }^{30}$ It is important here therefore to make a distinction between learning and assessing skilled communication. Salmon and Young ${ }^{25}$ may be correct when they contend that by assessing communication skills using a reductionist checklist, there is a risk of trivialising the communication interaction. This is particularly the case if assessment procedures require the demonstration of the many discrete communication skills proposed (ie, the 'parts') regardless of the context. Such rating requirements may inaccurately judge the 'whole'. 222532 However, breaking a complex phenomenon, like communication, into discrete 'parts' may allow a novice learner to appreciate what may be required for their own skill development. ${ }^{33}$ Targeted performance development and self-regulated learning require targeted learning goals: therefore, the clarification of these skills has the potential to be useful for learners and educators. ${ }^{34-36}$ Learning the component 'parts' of a communication interaction may allow for skill acquisition and improved performance of the 'whole'. ${ }^{37}$ With increased proficiency, learners would then be able to use these skills in a flexible, personal and creative way depending on the context. ${ }^{33} 38$

\section{Communication skills learning outcomes}

To the best of our knowledge, there is only one published review identifying communication skills learning outcomes relevant to multiple health professional groups. In 2013, Bachmann et $a l^{8}$ produced the European consensus on learning objectives (HPCCC: Health Professions Core Communication Curriculum). Bachmann et al use the term learning 'objective' in their report to which we attribute the same meaning as the term learning 'outcome'. The HPCCC presents learning objectives that are based on the literature and a medical communication consensus statement and were developed using an extensive Delphi process. In total, 121 communication experts from 16 countries and 15 professions reviewed learning objectives in four stages. Each stage included a review of drafts, ranking of statements and comments regarding acceptability. This process drew on a large community of practice within Europe that has a significant focus on communication in healthcare. The HPCCC presents learning objectives that go beyond 'health professional-patient' communication and target interprofessional and intraprofessional communication skills. However, the report omits the key quality indicator of detail about the literature review processes, subsequently limiting potential for replication. ${ }^{39}$ While the Delphi process and the quantitative and qualitative analysis methods were clearly described, the development of the initial draft list of statements is less clear. 


\section{Research aim}

The work presented here builds on the contributions of previous studies and aims to identify and analyse communication skills learning outcomes via a systematic review and to present the results in a synthesised list.

\section{METHODS}

\section{Methodology}

Research design

A systematic review of the literature (stage 1) was completed to assemble published learning outcomes relevant to health professional communication skills. A parsimonious set of learning outcomes was then developed through an explicit and iterative process of qualitative synthesis (stage 2).

\section{Research team}

The research team for stage 1 was the core research team (CD, EM, JLK). Researchers in the field (RW-K, DN, FK: see acknowledgements) joined the core researchers, expanding the research team to six for stage 2 of this study. The stage 2 team consisted of educational researchers, social scientists and an educational linguist based in medical education. Four of the members had clinical backgrounds (physiotherapy). The members had published extensively across health professions education and communication skills research in areas that included scale development, healthcare simulation education, communication skills teaching, curriculum and resource development, feedback and assessment, clinical education and interprofessional education. All members were actively involved in the education of prequalification and postqualification health professional students and medical education research.

\section{Theoretical perspective and guiding principles}

This work forms part of a broader research programme exploring the social construction of skilled communication in the health professions. According to social constructionism, knowledge and meaning are constructed through the interaction of a learner and the surrounding environment; therefore, multiple realities exist and there is no 'true' interpretation of a phenomenon. ${ }^{40}$ In this work, we did not set out to define a single truth in relation to learning targets for communication skills. Instead, we investigated published interpretations of this phenomenon and synthesised the findings for application in education. The research team considered that the results of this review would provide a foundation for others to interpret rather than a prescriptive list.

As a research team, we also ascribed to the notions of person-centredness during the qualitative synthesis phase of this study. Aligning with social constructionism, patient-centredness appreciates the individual and social dimensions of a phenomenon. Values of personcentredness including acknowledging patient-as-person and the multiple other persons involved in healthcare practice (eg, colleagues, students and the health professional themselves), and sensitivity to another's perspective and preferences ${ }^{41}$ informed the choice of language in the results of this work.

\section{Stage 1: systematic literature review}

The first stage of this work was a systematic literature review to identify published learning outcomes of health professional communication skills programmes.

\section{Inclusion and exclusion criteria}

For inclusion, papers must have described learning outcomes within an education programme targeting the development of communication skills. Participating learners had to be health professionals and could be of any health profession and level of education. Any statement describing what learners were expected to know and/or do after participation in a programme was included, irrespective of the terminology used (eg, learning outcomes, objectives, targets and goals). Knowledge, behavioural and attitudinal learning outcomes were included. Papers were excluded if not available in English, if the education targeted English language fluency or the learning outcomes related to improvement of communication disorders (eg, those related to deafness or aphasia). Any study design was eligible for review.

\section{Search strategy}

A comprehensive search was conducted in August 2016, on the full holdings of MEDLINE, PsycINFO, ERIC, CINAHL plus and Scopus databases. Search terms included health professional, communication, training and their synonyms. The strategy used to search OVID databases is presented in online supplementary appendix A. The full yield from each database was exported to a bibliographic management system and duplicates deleted. On the basis of the title and abstract, papers that were ineligible were deleted. The remaining papers were read in full, and their eligibility was assessed against the inclusion and exclusion criteria. The primary author (CD) independently reviewed all papers and consulted with authors JK and EM on papers when eligibility was difficult to determine.

\section{Data extraction}

Table 1 describes the data that were extracted from each paper. All data were descriptively analysed and synthesised for discussion. Learning outcomes described in each paper were extracted and referenced to the source using an alphanumeric identifier. They were pooled and common learning outcomes were collated under preliminary themes, and subthemes, in a process of thematic analysis for commonality. ${ }^{42}$ Preliminary thematic groups rendered the data set manageable for qualitative synthesis. The core research team (CD, EM, JLK) collaborated to delete duplicated learning outcomes (eg, those with exact wording) that were revealed as the learning outcomes were collated. 
Table 1 Items for data extraction

\begin{tabular}{|c|c|}
\hline Reference detail & Author (date of publication) \\
\hline Paper type & $\begin{array}{l}\text { Description of communication skills education, primary research or secondar } \\
\text { research }\end{array}$ \\
\hline Country of origin & Of the primary author \\
\hline Learner profession and specialty & Eg, Medicine, Oncology \\
\hline Type of learner & Prequalification or postqualification \\
\hline $\begin{array}{l}\text { Theoretical perspective underpinning the } \\
\text { educational intervention }\end{array}$ & Eg, Patient centredness \\
\hline Patient as stakeholder & $\begin{array}{l}\text { Did the paper report the engagement of patients in the development of the } \\
\text { reported education? }\end{array}$ \\
\hline Communication model used & $\begin{array}{l}\text { Eg, Calgary Cambridge Referenced Observation Guide, Kalamazoo } \\
\text { Consensus statement }\end{array}$ \\
\hline Intended learning outcomes & $\begin{array}{l}\text { Statements identifying intended learning outcomes; eg, descriptions of } \\
\text { outcomes, objectives, learning goals, learning targets, competencies, skills }\end{array}$ \\
\hline
\end{tabular}

- target one attribute/construct only

- describe an observable and measurable target

- be unambiguous, transparent and defensible

- be useful to students, educators and/or key stakeholders

- describe without jargon and have a self-evident meaning

- be culturally sensitive

- be concise

- be without value-laden terms

- be free of negative wording e.g. not or never

Figure 1 Decision guide.

\section{Quality analysis}

This work does not resemble a traditional systematic review, in that quality assessment was not carried out on the included papers as we were not attempting to establish the validity of the recommended learning objectives. A systematic review approach, however, was used to identify eligible papers to enable transparency and replication and to address the research aim. Aligning with this aim, our focus was to extract the learning outcomes used in education design and review the content and quality of these statements. In other words, we applied a quality assessment filter to the learning outcomes (see decision guide, figure 1), not to the papers themselves.

\section{Stage 2: qualitative synthesis}

In stage 2, learning outcomes identified in stage 1 were synthesised by the research team through an iterative process of individual, paired and group work. An initial meeting of the expanded research team was convened, and a random subset of learning outcomes was taken from the data set to rehearse the process of learning outcome synthesis. Synthesis was guided by the notions of personcentredness, and the decision guide is shown in figure 1. The decision guide was adapted from that used by Dalton ${ }^{43}$ in the refinement of assessment targets for competency to practice. This set of criteria was deemed the most fitting to guide the construction of learning outcomes. The decision guide was used to judge the quality of the learning outcomes and to address semantics in order to emphasise the important characteristics when constructing statements to be used for goal setting and practice. ${ }^{28} 3643$

Following this group meeting, the remaining learning outcomes were divided into five equivalent sections (eg, equivalent work per group member) and each member completed an individual review of one section. The primary author $(\mathrm{CD})$ reviewed all sections.

Following this individual work, the primary author met with each member to compare work. After consensus was reached on all five sections, the core research team (CD, EM, JLK) reviewed themes and subthemes to reflect the synthesised data set. The refined learning outcomes were returned to the full group for consideration with a request for individual review prior to finalisation. A final group meeting enabled consensus regarding content, definition of terms and structure and presentation of the document.

Throughout the synthesis process, the number of learning outcomes was reduced as the research group collapsed multiple learning outcomes into one representative learning outcome, as further duplicates were identified, and as the group modified learning outcomes to align with the decision guide (see table 2 for an example of the qualitative synthesis process). At each step of this iterative process, the research group engaged in discussion to resolve different interpretations of the data, to highlight concepts that were absent from the data set, to resolve inconsistencies in language/terms and to ensure the learning outcomes continued to reflect the source literature. The primary author (CD) made an audit trail of decisions throughout the analysis. The audit trail included clear documentation of the process to make transparent the methods used in learning outcome refinement. ${ }^{44}$

\section{RESULTS}

\section{Stage 1: literature review}

A total of 168 papers were included for review (figure 2). Full reference details of eligible papers are 
Table 2 Example of qualitative synthesis

Learning outcomes identified in the stage one literature review

Start and end a conversation appropriately

Interview in a logical fashion

Control the interview by encouraging the patient to keep to the point

Providing structure to the consultation

The model of the structure and sequence of effective doctor-patient communication

Shapes a conversation from beginning to end with regard to structure in acute situations

Structure the interview

Individual synthesis by primary author

Directs the conversation

Shows the structured interview/consultation process

Shapes a conversation from beginning to end with regard to structure

Primary author and group member paired synthesis

Guide a healthcare interaction from beginning to end with regard to logical flow

After final group review

Guide a healthcare interaction from beginning to end to establish a logical flow

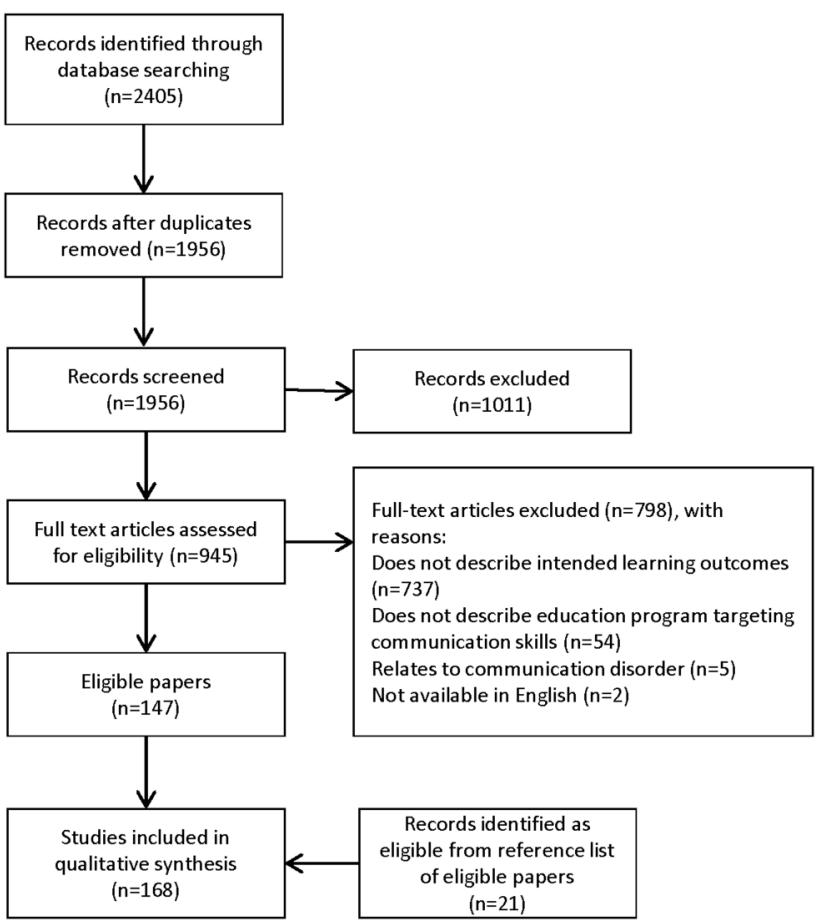

Figure 2 Flow of papers into the review.

presented in online supplementary appendix B; further details are available on request from the primary author. A summary is presented below and in table 3 .

The highest proportion of included papers was primary research $(64 \%)$. There was a variety of study designs including randomised controlled trials investigating change in behaviour and posteducation learner evaluations. The majority of papers were published between 2010 and August 2016 (46\%), originated from the USA $(56 \%)$, described communication teaching in medicine $(55 \%)$ and in qualified health professionals $(56 \%)$. Learners in oncology $(10 \%)$ outnumbered learners in other fields of practice. Learners in second year were most common in the prequalification population $(8 \%)$.
Many papers did not report a theoretical perspective of their work $(58 \%)$; of those that did, the most common perspective reported was patient-centred care principles $(7 \%)$.

Many included papers (40\%) did not report any specific communication models that informed teaching. If cited, the most frequent models were the Kalamazoo Consensus Statement (7\%), Calgary-Cambridge Referenced Observation Guides $(5 \%)$ and the Three Functions of the Medical Interview $(5 \%)$; a variety of other communication models were reported $<4 \%$ of the time. Other factors that informed educational design were stakeholder engagement, with $51 \%$ of reports documenting turning to clinicians, researchers and the literature to design the learning outcomes of their programmes. Only 5\% reported engaging patients as stakeholders in the development of programmes.

A total of 1669 learning outcomes for communication skills education were extracted from eligible papers; duplicated learning outcomes were deleted, reducing the list to 1073 .

\section{Stage 2: qualitative synthesis}

The 1073 learning outcomes identified in stage 1 were condensed to a final set of 205 learning outcomes (figure 3). The learning outcomes are presented in themes of 'knowledge', 'content', 'process' and 'perceptual' skills. Three of these themes are based on the seminal work of Kurtz, Silverman and Draper. ${ }^{45}$ The research group added a fourth theme, knowledge (see table 4 for detailed definitions and other terms used in the final learning outcomes document). 'Knowledge' learning outcomes made up $20 \%$ of the final list of learning outcomes. They relate to knowledge of the characteristics and modes of communication in healthcare and how emotions and relationships affect communication in healthcare. Learning outcomes within the 'content' and 'process' themes dominate the literature and therefore are represented heavily in the final set $(36 \%$ and $35 \%$, 


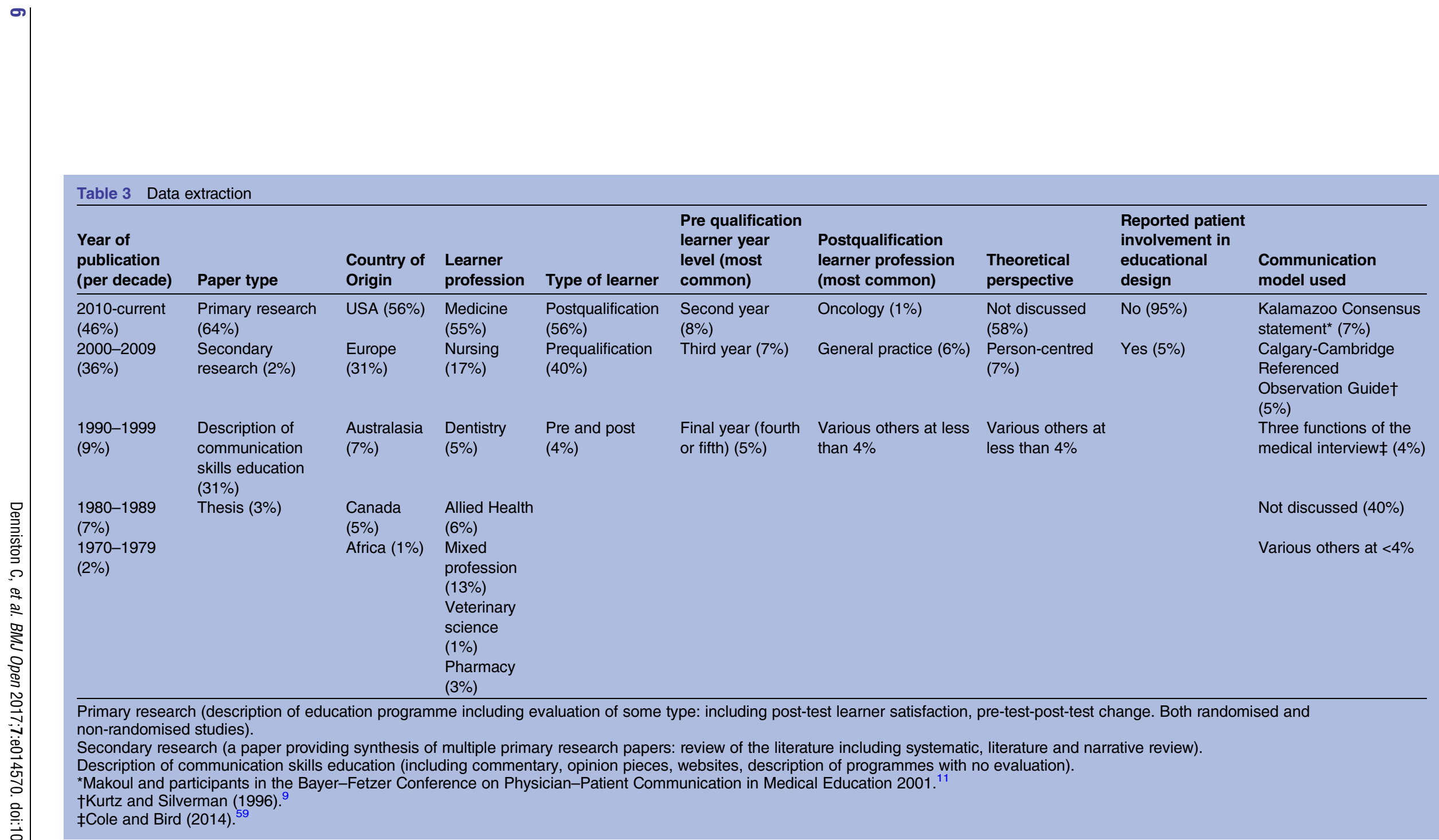




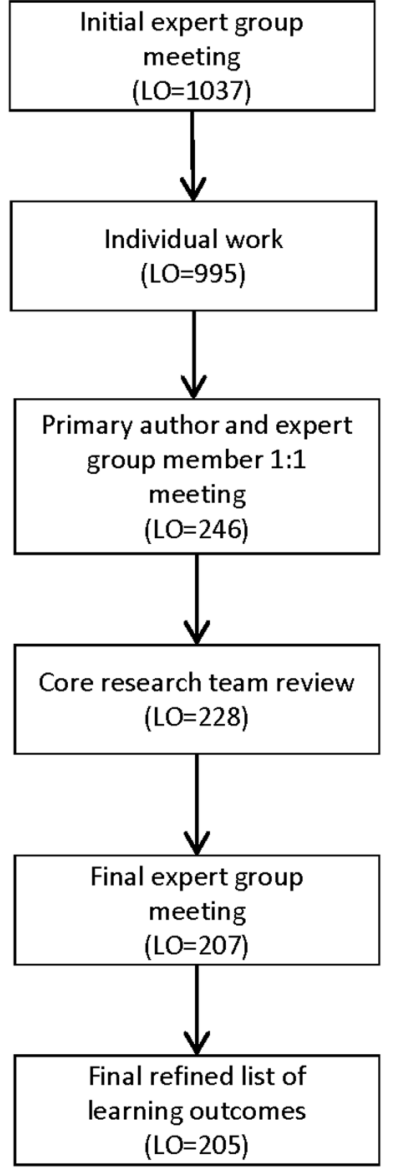

Figure 3 Flow of learning outcome (LO) refinement.

respectively). These learning outcomes include the important 'what' and 'how' of communication skills. ${ }^{46}$ The learning outcomes within the content domain have been presented in the chronological sequence of a healthcare interaction for ease of representation. ${ }^{47} 48$ Learning outcomes under the 'perceptual' skill theme made up $9 \%$ of learning outcomes in the final results. This final list of learning outcomes covers a wide range of skills proposed for communication teaching and is presented in online supplementary appendix C.

\section{DISCUSSION}

The aim was to identify and analyse communication skills learning outcomes via a systematic review and present results in a synthesised list for consideration and use by educators and researchers across the health professions. From 168 included papers, 205 learning outcomes for communication skills evolved through qualitative synthesis. As far as we are aware, no previous review has reported on a comprehensive systematic literature review to identify learning outcomes for communication skills and presented them for uptake across the health professions.

\section{What did we learn about communication skills learning outcomes?}

Patients are less likely to be involved in education design

Patient-centred communication is considered fundamental to effective healthcare delivery, but these principles are not consistently used as a basis for communication skills teaching, with only $7 \%$ of papers reporting patientcentred care as an underpinning theoretical perspective. In addition, only 5\% of papers reported engaging patients in any aspect of educational design. Although valued in health professions education, patient engagement is not well defined. ${ }^{49}$ Regan de Bere and Nunn ${ }^{50}$ have proposed ideas for the future pedagogy of patient (and public) involvement in health profession education. It seems appropriate that future communication skills educational design follows this lead and engages patients (and public) in the design of teaching and learning to explore what patients expect from health professionals, in terms of communication, as well as to acknowledge patients and patient-centred care as a unifying focus in health professions education. ${ }^{50}$

\section{Knowledge and perceptual skills are less common}

Unlike the learning outcomes reported in the HPCCC, this paper includes learning outcomes relating to behaviour and knowledge. Knowledge forms part of the initial phases of scaffolding for learning and assessment, ${ }^{51}$ and in learning theories describing skill development, a learner usually needs to know the terms and context of behaviour before they learn the behaviour itself. ${ }^{52}$ In the past, knowledge-based learning outcomes have been criticised for being overemphasised in approaches to educational design, at the expense of behavioural learning outcomes. ${ }^{18}$ In the communication skills literature, perhaps the emphasis has swung too far away from the

Table 4 Final learning outcomes: themes and definitions

\begin{tabular}{ll}
\hline Theme & Definition \\
\hline Knowledge & $\begin{array}{l}\text { An individual's understanding of information through which incoming data and/or experiences are processed } \\
\text { and recorded }\end{array}$ \\
$\begin{array}{l}\text { Content } \\
\text { Process }\end{array}$ & $\begin{array}{l}\text { How is communicated }(\mathrm{eg}, \text { what learners do/say in communication interactions) } \\
\text { Awareness of self and others and how that impacts communication }(\mathrm{eg}, \text { thoughts, feelings, attitudes and } \\
\text { berceptual }\end{array}$ \\
$\begin{array}{l}\text { Terms used } \\
\text { Personal } \\
\text { context }\end{array}$ & $\begin{array}{l}\text { Perspective of the individual as influenced by: age, gender, health literacy, socioeconomic status, } \\
\text { education, culture, ethnicity, language, religion, present emotional/physical state }\end{array}$ \\
\hline
\end{tabular}


knowledge agenda with most publications only reporting behavioural learning outcomes. The presented list brings communication skills in line with other skills teaching, by acknowledging the integration of knowledge and behaviour in 'technical' skill development. ${ }^{28}$

Learning outcomes under the perceptual skill theme made up only $9 \%$ of learning outcomes in the final results. These learning outcomes relate to awareness and evaluation of self, others and context, which are considered important in reflective, self-regulating health professionals. ${ }^{34} 53$ Despite ample literature promoting reflective practice in the health professions education field in general, ${ }^{54}$ published programmes on communication skill development seem less focused on incorporating learning objectives to target these evaluative skills. The low level of reporting of perceptual skill objectives may reflect the challenge in defining these skills so that they are objective and measurable. Healthcare communication is unique, complex and nuanced, and therefore objectivity when defining these desired communication skills can be elusive. ${ }^{26}$ However, clearly articulating these important skills is key to defining learning goals for performance development.

\section{Language can be modified for greater application}

During the qualitative synthesis process, the research group identified many of the learning outcomes that were specific to communication with a patient but that could equally apply to other communication interactions. The term 'patient' appeared in many included learning outcomes and was replaced in the refined list with the term 'healthcare seeker'. The term healthcare seeker was more broadly applicable across healthcare contexts and acknowledged the active role that an individual can have in regard to his/her health. While the original learning outcome may have referred to communication between a health professional and care seeker, in some instances we found that learning outcomes could be easily reshaped to apply to communication with a different 'communication partner' entirely (eg, colleague or student). This parallel between skills in a therapeutic interaction and a collegial or educational interaction has been identified by others. ${ }^{55} 56$

The research team also replaced all profession-specific terms identifying the target learner (eg, dentist) with the term 'health professional' as most learning outcomes had potential application to a variety of professions. The identification of these common learning outcomes may provide a platform for interprofessional education and facilitate a shift from 'siloed' health professional education to 'collaborative' practice, and education, within which communication is considered an essential common skill. ${ }^{57}$

\section{Learning objectives are often unclear or absent}

Previous reviews reporting communication skills in medical education have criticised the quality of published learning outcomes, reporting that they were unclear or absent in many papers on communication education. ${ }^{47} 58$ This was reflected in the current review with only 208 papers, of the 945 full text screened, reporting specific learning outcomes for the education described. Like Cegala and Lenzmeier Broz ${ }^{47}$ the authors acknowledge that the word count of many journals limits the inclusion of exhaustive lists of learning outcomes. However, even when learning outcomes were reported, they often targeted two to three constructs per statement, included value-laden words such as 'good' (eg, use good nonverbals) and many were ambiguous in their intention (eg, be able to apply the necessary communication skills adequately in a simulation). During stage 2 qualitative synthesis, the use of the decision guide focused attention on the design features of useful learning outcomes and guided the synthesis process. For example, many learning outcomes such as 'show empathy' were not accompanied by a descriptor or defined example; this rendered them neither useful, nor measurable or transparent (see figure 1, decision guide). For learning outcomes such as this, we made the decision to combine all learning outcomes describing 'empathic' behaviour under a single learning outcome 'demonstrate empathy in the following ways': after which a list of observable behaviours were assembled (see item no. 136 in online supplementary appendix C). This method of illustrating these 'slippery' learning outcomes, with observable behaviours, aimed to shape the learning outcome into a useful, measurable and transparent structure that would guide educators and learners.

\section{Study strengths and limitations}

This paper has a number of limitations. By casting a wide net in this literature review, we drew from the worldwide interest in this topic. In targeting a breadth of perspectives, we identified diverse studies, from educators across professions, which informed the results. A side effect of the broad search was the challenge of dealing with a large amount of data. Multiple stages of thematic analysis and refinement were required to create a manageable data set. The process of refinement necessarily included removal or rewording of items. We cannot be sure that this has not led to omissions in the final set of learning outcomes. However, the iterative nature of the qualitative synthesis process meant that all attempts were made to produce a representative list. Although these results represent a wide range of literature, they do not include input from other key stakeholders (ie, care seekers, representatives from different healthcare professions, learners and educators). Therefore, we do not claim that this is a complete list of learning outcomes illustrative of all stakeholders' needs. By focusing on specific communication skills education, we may have excluded communication learning outcomes in patient safety or clinical reasoning education programmes. In addition, we excluded papers reporting on communication disorders or English language 
fluency which may have also provided relevant learning outcomes.

\section{Implications for practice and future research}

This work provides educators and learners with a comprehensive set of learning outcomes for educational design and goal setting in healthcare communication. Aligning with a social constructionist perspective, we invite stakeholders to take these learning objectives and reinterpret them based on their context. This work may prompt educators to reflect on how knowledge and perceptual skills are taught in domains such as communication and to encourage educators to be cognisant of the quality of the learning outcomes they design.

Further research is required to interrogate these learning outcomes for accuracy and completeness by engaging with stakeholders (including care seekers) to align targets for learning with targets for practice. Future research might also explore the parallels between communication skills needed in care seeker interactions and those required for other healthcare conversations (eg, between healthcare professionals, trainees or policymakers). Perhaps by positioning communication skills as skills that are required with any 'communication partner', we can equalise the gravitas generally afforded to 'doctor-patient' communication in this field of literature.

\section{CONCLUSIONS}

This paper presents a synthesis of the vast literature in communication skills teaching and a list of 205 learning outcomes. These learning outcomes have been categorised into four domains and provide educators from across the healthcare professions with a basis from which to develop learning goals and programmes relevant to their setting.

Acknowledgements The authors acknowledge Dr Fiona Kent for her contribution to the qualitative synthesis phase of this review.

Contributors CD, EM and JLK designed the work. CD conducted the systematic review search and data extraction in stage 1. All authors (CD, EM, JLK, DN and RW-K) were involved in qualitative synthesis and analysis in stage 2. CD drafted the first version of the manuscript. All authors reviewed and revised the manuscript and approved the final version.

Funding This research received no specific grant from any funding agency in the public, commercial or not-for-profit sectors.

Competing interests None declared.

Provenance and peer review Not commissioned; externally peer reviewed.

Data sharing statement No additional data are available.

Open Access This is an Open Access article distributed in accordance with the Creative Commons Attribution Non Commercial (CC BY-NC 4.0) license, which permits others to distribute, remix, adapt, build upon this work noncommercially, and license their derivative works on different terms, provided the original work is properly cited and the use is non-commercial. See: http:// creativecommons.org/licenses/by-nc/4.0/

\section{REFERENCES}

1. Higgs J, McAllister L, Sefton A. Communication in the health sciences. 3rd edn. South Melbourne, Victoria, Australia: Oxford University Press, 2012:368.
2. O'Keefe M, Henderson A, Pitt R. Health, medicine and veterinary science: Learning and teaching academic standards statement. New South Wales, Australia: Australian Government Department of Education, Employment and Workplace Relations, 2011.

3. Royal College of Physicians and Surgeons of Canada. CanMEDS Physician Competency Framework-Communicator. Secondary CanMEDS Physician Competency Framework-Communicator. 2015. http://www.royalcollege.ca/portal/page/portal/rc/canmeds/ framework/communicator

4. Chartered Society of Physiotherapy. Q.A. standards. Section 7: communication. Secondary Q.A. standards. Section 7: communication. 2015. http://www.csp.org.uk/professional-union/professionalism/ csp-expectations-members/quality-assurance-standards/section-7-co

5. Interprofessional Education Collaborative Expert Panel. Core competencies for interprofessional collaborative practice: report of an expert panel. Washington: Interprofessional Education Collaborative, 2011.

6. Silverman J. Teaching clinical communication: a mainstream activity or just a minority sport? Patient Educ Couns 2009;76: 361-7.

7. Brown J. How clinical communication has become a core part of medical education in the UK. Med Educ 2008;42:271-8.

8. Bachmann C, Abramovitch H, Barbu CG, et al. A European consensus on learning objectives for a core communication curriculum in health care professions. Patient Educ Couns 2013;93:18-26.

9. Kurtz SM, Silverman JD. The Calgary-Cambridge Referenced Observation Guides: an aid to defining the curriculum and organizing the teaching in communication training programmes. Med Educ 1996;30:83-9.

10. von Fragstein M, Silverman J, Cushing A, et al. UK consensus statement on the content of communication curricula in undergraduate medical education. Med Educ 2008;42:1100-7.

11. Makoul G, Participants in the Bayer-Fetzer Conference on Physician-Patient Communication in Medical Education. Essential elements of communication in medical encounters: the Kalamazoo consensus statement. Acad Med 2001;76:390-3.

12. Kiessling $C$, Dieterich A, Fabry G, et al. Communication and social competencies in medical education in German-speaking countries: The Basel Consensus Statement. Results of a Delphi survey. Patient Educ Couns 2010;81:259-66.

13. Mager R. Preparing instructional objectives. Palo Alto (CA): Fearon Publishers, 1962.

14. Biggs J. Enhancing teaching through constructive alignment. High Educ 1996;32:347-64.

15. Cross DS, Rodgers AT, Tilson ER. Competency, objectives and outcomes. Radiol Technol 2000;71:487.

16. Harden RM. Learning outcomes and instructional objectives: Is there a difference? Med Teach 2002;24:151-5.

17. Touchie $\mathrm{C}$, ten Cate $\mathrm{O}$. The promise, perils, problems and progress of competency-based medical education. Med Educ 2016;50:93-100.

18. Frank JR, Snell LS, Cate OT, et al. Competency-based medical education: theory to practice. Med Teach 2010;32:638-45.

19. Grant J. Principles of curriculum design. In: Swanick T, ed. Understanding medical education: evidence, theory and practice. 2nd edn. London: John Wiley \& Sons, 2014:31-46.

20. Prideaux D. The emperor's new clothes: from objectives to outcomes. Med Educ 2000;34:168-9.

21. Prideaux D. Curriculum design. BMJ 2003;326:268-70.

22. Prideaux D. The emperor's new wardrobe: the whole and the sum of the parts in curriculum design. Med Educ 2016;50:10-12.

23. Rees CE. The problem with outcomes-based curricula in medical education: insights from educational theory. Med Educ 2004;38:593-8.

24. Grant J. The incapacitating effects of competence: a critique. Adv Health Sci Educ Theory Pract 1999;4:271-7.

25. Salmon $P$, Young B. Creativity in clinical communication: from communication skills to skilled communication. Med Educ 2011;45:217-26.

26. Salmon $\mathrm{P}$, Young $\mathrm{B}$. The validity of education and guidance for clinical communication in cancer care: evidence-based practice will depend on practice-based evidence. Patient Educ Couns 2013;90:193-9

27. van Dalen J. Communication skills in context: trends and perspectives. Patient Educ Couns 2013;92:292-5.

28. Nestel D, Walker $K$, Simon $R$, et al. Nontechnical skills: an inaccurate and unhelpful descriptor? Simul Healthc 2011;6:2-3.

29. Wouda JC, van de Wiel HB. Education in patient-physician communication: how to improve effectiveness? Patient Educ Couns 2013;90:46-53. 
30. Zoppi K, Epstein RM. Is communication a skill? Communication behaviors and being in relation. Fam Med 2002;34:319-24.

31. Plum A. Communication as skill: a critique and alternative proposal. $J$ Humanist Psychol 1981;21:3-19.

32. van den Eertwegh V, van Dulmen S, van Dalen J, et al. Learning in context: Identifying gaps in research on the transfer of medical communication skills to the clinical workplace. Patient Educ Couns 2013;90:184-92.

33. Dreyfus H, Dreyfus SE. Five steps from novice to expert. Mind over machine: the power of human intuition and experise in the era of the computer. New York (NY): Simon and Schuster, 2000.

34. Berkhout JJ, Helmich E, Teunissen PW, et al. Exploring the factors influencing clinical students' self-regulated learning. Med Educ 2015;49:589-600.

35. O'Neill G, Donnelly R, Fitzmaurice M. Supporting programme teams to develop sequencing in higher education curricula. Int $J$ Acad Develop 2014;19:268-80.

36. Sadler DR. Formative assessment and the design of instructional systems. Instr Sci 1989;18:119-44.

37. Magill RA. Motor learning and control: concepts and applications. 7th edn. Boston (MA): McGraw-Hill, 2004.

38. Deveugele M. Communication training: Skills and beyond. Patient Educ Couns 2015;98:1287-91.

39. Moher D, Liberati A, Tetzlaff J, et al. Preferred Reporting Items for Systematic Reviews and Meta-Analysis: The PRISMA Statement. PLoS Med 2009;6:e1000097.

40. Crotty M. Constructionism: the making of meaning. The foundations of social research: meaning and perspective in the research process. St Leonard, Australia: Allen \& Unwin, 1998:42-65.

41. Mead N, Bower P. Patient-centredness: a conceptual framework and review of the empirical literature. Soc Sci Med 2000;51:1087-110.

42. Gibson WJ, Brown A. Working with qualitative data. London, UK: Sage, 2009

43. Dalton MB. Development of the assessment of physiotherapy practice: a standardised and validated approach to assessment of professional competence in physiotherapy [dissertation]. Monash University, 2011.

44. Rodgers BL, Cowles KV. The qualitative research audit trail: a complex collection of documentation. Res Nurs Health 1993;16:219-26.
45. Kurtz S, Silverman J, Draper J. Teaching and learning communication skills in medicine. Oxford: Radcliffe Medical Press, 1998.

46. Kurtz S, Silverman J, Benson J, et al. Marrying content and process in clinical method teaching: enhancing the Calgary-Cambridge Guides. Acad Med 2003;78.

47. Cegala DJ, Lenzmeier Broz S. Physician communication skills training: a review of theoretical backgrounds, objectives and skills. Med Educ 2002;36:1004-16.

48. Veldhuijzen W, Ram PM, van der Weijden T, et al. Communication guidelines as a learning tool: an exploration of user preferences in general practice. Patient Educ Couns 2013;90:213-19.

49. Rees CE, Knight LV, Wilkinson CE. "User Involvement Is a Sine Qua Non, Almost, in Medical Education": learning with rather than just about health and social care service users. Adv Health Sci Educ Theory Pract 2007;12:359-90.

50. Regan de Bere S, Nunn S. Towards a pedagogy for patient and public involvement in medical education. Med Educ 2016;50: 79-92.

51. Miller GE. The assessment of clinical skills/competence/ performance. Acad Med 1990;65:S63-7.

52. Benner P. From novice to expert. Am J Nurs 1982;82:402-7.

53. Kurtz SM. Doctor-patient communication: principles and practices. Can J Neurol Sci 2002;29(Suppl 2):S23-9.

54. Mann K, Gordon J, MacLeod A. Reflection and reflective practice in health professions education: a systematic review. Adv Health Sci Educ Theory Pract 2007;14:595-621.

55. Telio S, Ajjawi R, Regehr G. The "educational alliance" as a framework for reconceptualizing feedback in medical education. Acad Med 2015;90:609-14.

56. Sommer J, Lanier C, Perron NJ, et al. A teaching skills assessment tool inspired by the Calgary-Cambridge model and the patient-centered approach. Patient Educ Couns 2016;99:600-9.

57. Frenk J, Chen L, Bhutta ZA, et al. Health professionals for a new century: transforming education to strengthen health systems in an interdependent world. Lancet 2010;376:1923-58.

58. Hulsman RL, Ros WJG, Winnubst JAM, et al. Teaching clinically experienced physicians communication skills. A review of evaluation studies. Med Educ 1999;33:655-68.

59. Cole SA, Bird J. The medical interview: The three function approach 3rd edn. Philadelphia (PA): Elsevier Saunders, 2014. 